\title{
Poder, saber e subjetivação: experiência de um grupo de saúde
}

Power, knowledge and subjetivation: a health group experience.

Poder, saber y subjetivación: experiencia de un grupo de salud

\section{Ana Carolina Perella}

Faculdade Juvêncio Terra, Vitória da Conquista, BA, Brasil.

João Leite Ferreira Neto

Pontificia Universitaria Católica de Minas Gerais, Belo Horizonte, MG, Brasil.

\begin{abstract}
Resumo
Análise da experiência do grupo "Comissão de Saúde" do bairro Rosaneves, município de Ribeirão das Neves/MG, enfocando suas relações de poder, saber e subjetivação. Realizou-se um estudo de caso sobre a trajetória do grupo, mediante análise documental, observação participante e entrevistas semi-dirigidas. Foi possível observar que a Comissão de Saúde, enquanto experiência, possibilitou mudanças nos modos de subjetivação das pessoas envolvidas no desenvolvimento do grupo, na medida em que desencadeou a invenção de novas possibilidades de vida e inserção social. Ou seja, os participantes do grupo puderam transformar a si a partir do seu encontro com o outro e com o espaço social onde estavam inseridos. Os processos grupais estudados demonstraram ser uma luta social e subjetiva à medida que deu visibilidade às demandas coletivas do bairro Rosaneves como também às pessoas envolvidas naquele processo.
\end{abstract}

Palavras-chave: Políticas Públicas, Subjetividade, Relações de Poder, Processos Grupais.

\begin{abstract}
This article analysis the experience of the group "Health Commission" from Rosaneves neighborhood, Ribeirão das Neves county, MG, focusing on of power, knowledge and subjectivity relations. A case study was accomplished. It was about the trajectory of the group, through document analysis, participant observation and semi-structured interviews. The "Health Commission", while being an experience, made changes in the ways of subjetivation of the people involved in the development of the group, were being triggered the invention of new possibilities of life and social insertion. Group members were able to transform itself from its meeting with the other one and with the social space where they lived. The group process with were studied has proved to be in a social struggle and subjectiv,
\end{abstract}


while being able to show the visibility towards collective demands from Rosaneves neighborhood as well as the visibility of the people who were involved in that process.

Keywords: Public Policies, Subjectivity, Power Relations, Group Processes.

\section{Resumen}

Análisis de la experiencia del grupo "Comisión de Salud" del barrio Rosaneves, municipio de Ribeirão das Neves/MG, en el que se enfocan las relaciones de poder, saber y subjetivación. Se realizó estudio de caso sobre la trayectoria del grupo, mediante un análisis documental, observación participante y entrevistas semi-dirigidas. Se pudo observar que la Comisión de Salud, como experiencia, permitió cambios en los modos de subjetivación de las personas involucradas en el desarrollo del grupo, en la medida en que desencadenó la creación de nuevas posibilidades de vida e inserción social. Es decir, los participantes del grupo pudieron transformarse a sí mismos a partir del encuentro con el otro y con el espacio social en el que estaban insertados. Los procesos grupales estudiados demostraron que eran una lucha social y subjetiva conforme iban dando visibilidad a las demandas colectivas del barrio, así como también a las personas involucradas en aquel proceso.

Palabras-clave: Políticas Públicas, Subjetividad, Relaciones de Poder, Procesos Grupales.

A questão central desenvolvida no presente artigo diz respeito à produção de subjetividades engendradas a partir da experiência de uma comissão de saúde do bairro Rosaneves, na cidade de Neves. O trabalho discute o que são as políticas públicas e o seu modo de funcionamento, bem como os seus efeitos nos modos de subjetivação dos seus usuários, principalmente, naqueles envolvidos com o Programa Mediação de Conflitos (PMC). Para embasar a discussão teórica, recorreuse à obra de Michel Foucault e de outros estudiosos da temática.
Seu ponto de partida foi a atuação da pesquisadora enquanto profissional de uma política pública do Estado de Minas Gerais, especificamente do Programa Mediação de Conflitos (PMC), posto que a formação da Comissão de Saúde de Rosaneves está estreitamente vinculada ao funcionamento do Programa mencionado.

O acompanhamento do grupo foi realizado durante os dois primeiros anos de sua existência, entre 2008 a 2010. Observou-se, nesses anos, que à medida que os moradores do bairro, especificamente os envolvidos no processo grupal, se apropriavam da Comissão de 
Saúde, além do ensejo de mudanças nos processos sociais, ocorreram transformações em seus modos de pensar, de agir e de sentir também ocorriam.

Importa esclarecer que, após dois anos de acompanhamento do grupo, a pesquisadora se desligou do Programa Mediação de Conflitos, desempenhando apenas a função de investigadora, entre abril de 2010 e Julho de 2011. Por conseguinte, acredita-se que a saída do PMC, em 2010, contribuiu para pensar com mais clareza sobre os processos em curso, posto que transitar pelos dois papéis, técnica social de uma política pública e pesquisadora, facultou a construção de um pensamento crítico e reflexivo acerca da vivência do grupo estudado, principalmente no que concerne aos atravessamentos do PMC na prática grupal.

Assumimos a importância do olhar crítico sobre a atuação do psicólogo no âmbito das políticas públicas, pois se trata "de um terreno minado, complexo e eivado de paradoxos. [...] é necessário sustentar uma postura menos ingênua e realizar um diagnóstico bem feito das relações de poder onde o mesmo está sendo desenvolvido" (Ferreira Neto, 2011, p. 31).

Partindo do princípio de que toda relação social é atravessada por relações de poder e que estas não somente exercem um papel repressivo, mas também produtivo, uma vez que tais relações produzem efeitos de saber, de subjetividade e de lutas (Revel, 2005), buscou-se com a pesquisa realizada, investigar os elementos de poder, de saber e de subjetivação presentes na experiência do grupo citado. Para Foucault (2006b, p. 262), "é a experiência, que é a racionalização de um processo ele mesmo provisório, que redunda em um sujeito, ou melhor, em sujeitos".

\section{Políticas públicas e produção de subjetividades}

De acordo com Rodrigues (2010) as políticas públicas se referem diretamente à ação do Estado face às demandas e necessidades da sociedade. Em outras palavras, as políticas públicas concernem na tentativa do Estado em resolver conflitos de ordem pública por meio da tomada de decisões coletivas e, em decorrência disso, do desenvolvimento de ações estratégias, visando melhores condições de vida para a população. "É sob essa lógica que as políticas públicas são desenhadas e formuladas", afirma Santos (2006, p. 26). Este autor vai mais além quando diz que as políticas públicas, por fim, "desdobram-se em planos, programas, projetos, bases de dados ou sistema de informação e pesquisas". Assim, quando postas em prática, elas "são 
implementadas, ficando daí, submetidas a sistemas de acompanhamento e avaliação". (Santos, 2006, p. 26)

Nesse prisma, falar sobre as políticas públicas é discursar sobre a relação entre Estado e sociedade, abordando os aspectos políticos e econômicos implicados em tal relação. Esta ideia é reforçada por Santos (2006) ao destacar que as políticas públicas incidem tanto na economia quanto na sociedade, daí o motivo pelo qual de qualquer teoria geral da política pública necessitar também elucidar as inter-relações entre Estado, política, economia e sociedade. Além dessas inter-relações, abordadas pela autora acima, faz-se necessário pensar e abordar nesse trabalho a relação entre políticas públicas e subjetividade, pois as ações daquelas incidem nos processos de subjetivação e de produção de subjetividades.

Para explicar as noções de subjetivação e subjetividade, abordadas nesse artigo, nos apoiamos em Foucault pelo fato deste compreender tais conceitos em sua relação com um contexto social, histórico, político e econômico. Fica visível que, para esse pensador, as transformações ocorridas na sociedade são acompanhadas de mudanças nos modos de subjetivação dos indivíduos.
Deste modo, Foucault compreende o sujeito não como algo acabado, padronizado, universal, ou interiorizado, concepção esta baseada nas filosofias do sujeito, de Descartes e de Sartre (Revel, 2005, p. 53). Pelo contrário, Foucault (2011, p. 7) entende o sujeito como um processo atrelado a uma "trama histórica". Daí, o motivo pelo qual o pensamento de Foucault manifesta-se como uma crítica às ideias essencialistas no tocante aquela noção de sujeito.

A partir dessa perspectiva foucaultiana, Revel (2005, p. 84) diz que "trata-se, portanto de pensar o sujeito como um objeto historicamente constituído sobre a base de determinações que lhe são exteriores". Ou seja, a subjetivação, entendida aqui como a maneira pela qual "se obtém a constituição de um sujeito, mas precisamente de uma subjetividade", é problematizada por Foucault como um processo engendrado em conexão com o exterior (Foucault, 2006b, p. 262).

Nessa ótica, pode-se dizer que a subjetividade se constitui em uma experiência histórica por meio de práticas e tecnologias de saber, de poder e de si. Portanto, quando recorremos em nossos estudos à noção de subjetividade, tal qual pensada por Foucault, estamos referindo a um processo no qual um conjunto de técnicas e práticas são engendradas, a 
partir de determinados fatores ou instâncias que são postas em conexão, afetando assim os modos de subjetivação do indivíduo.

Foucault também nos ajuda a refletir sobre as políticas públicas ao concebê-las, a partir da constituição do Estado Moderno (XVIII-XXI), como forma de gestão da vida dos indivíduos e da população. Foi durante esse período que a vida dos sujeitos tornou-se objeto de atenção e de estratégias políticas de governo, ocorrendo assim "a assunção da vida pelo poder" (Foucault, 2005, p. 285286).

É a partir do final do sec. XVII, segundo o autor mencionado, que se vê surgir duas tecnologias de poder, conhecidas como disciplina e biopolítica, que compõem o chamado biopoder. $\mathrm{O}$ poder sobre a vida, como tal conceito é definido por Foucault (2005), é exercido em duas dimensões, são elas: polo corpo (poder disciplinar) e polo população (poder biopolítico).

Conforme Foucault (2009, p. 203), no polo corpo a disciplina ou a "anatomia do poder" surge no decorrer dos séculos XVII e XVIII como uma técnica de poder centrada no corpo individual. Essa tecnologia de poder "fabrica assim corpos submissos e exercitados, corpos dóceis. A disciplina aumenta as forças do corpo (em termos econômicos de utilidade) e diminuiu essas mesmas forças (em termos políticos de obediência)" (Foucault, 2009, p.133). Nesse prisma, as disciplinas, ao exercerem relações de poder-saber nos corpos dos indivíduos, fazem funcionar novos mecanismos de sanção normalizadora. Com isso, caracterizam, homogeneízam, hierarquizam, classificam os indivíduos; dividem-nos em torno de uma norma, e até, por fim, os desqualificam e os invalidam.

No polo população a tecnologia de poder toma por foco o governo da população. Ou seja, esta se torna o objeto de preocupação e de investimento político, passando então a ser vista como um conjunto de fenômenos naturais com dinâmicas próprias e não mais pensada como uma "coleção de súditos" (Foucault, 2008, p. 473), que promovia a força do soberano como na soberania clássica. Pensar a população como "uma realidade muito mais densa, espessa, natural" (Foucault, 2008, p.473) implica mudanças nas táticas e nas técnicas políticas. Isto não quer dizer que a tecnologia disciplinar tenha sido substituída pela biopolítica, pelo contrário, esta surge para complementar à gestão da vida, uma vez que o poder do sec. XVIII "se incumbiu tanto do corpo quanto da vida, ou que se incumbiu, [...] da vida em geral, com o polo do corpo e o 
polo da população" (Foucault, 2005, p. 302).

Em função do exposto, pode-se dizer que novos desafios políticos foram empreendidos. Ou seja, conforme Foucault (2005), não se trata mais de se preocupar com o indivíduo no seu mínimo detalhe, ou ainda, não se trata mais de ter unicamente como objeto político o corpo individual. Ao contrário disso, trata-se de preocupar, concomitantemente, com a população, com a massa, ou seja, trata-se de atingir os problemas que possam colocar em risco a coletividade.

Assim, doravante vai ser necessária a implantação de políticas públicas que assegurem à saúde, a alimentação, a moradia, a segurança, o transporte, entre outras. Isso faz pensar que as políticas públicas de caráter social se tornaram uma das ferramentas utilizadas pela biopolítica para assegurar a vida, ou melhor, para o “fazer viver" (Foucault, 2005, p.294).

Por conseguinte, o Estado ao objetivar a gestão da vida, por meio dessa estratégia política de governo, toma a população como alvo da ação governamental, tornando-a potencialmente governável. Nessa lógica, as políticas públicas em nome da vida podem ditar aos seus usuários modos de ser, de estar e de viver no mundo, assujeitando-os com suas práticas normalizadoras e reguladoras.
Percebe-se, assim, que tanto a técnica de poder disciplinar quanto a biopolítica se fazem presentes na busca da maximização da vida a partir do funcionamento das políticas públicas, sendo que a primeira, através de um saber institucionalizado, é “capaz de dizer como os indivíduos devem agir e até mesmo como pensar os diversos momentos de suas atividades sociais" (Guareschi, Lara \& Adegas, 2010, p. 335). Já a segunda, de acordo com os autores, irá intervir no fenômeno da população a partir de diversas formas de governo, quais sejam, tratamento, prevenção, educação, regulação e promoção de vida, buscando garantir a todo o gradiente populacional (idosos, crianças, analfabetos, doentes mentais) melhores condições de vida.

Enfim, as políticas públicas a partir de todo o seu conjunto de práticas, de técnicas e de discursos, exercem de alguma maneira efeitos na produção da subjetividade de seus usuários. Ao mesmo tempo em que assujeitam os modos de vida de seus usuários, por meio de uma padronização de condutas, tais políticas deixam "brechas" para a construção de novos estilos de vida, uma vez que a constituição do sujeito se dá concomitantemente através de relações de poder-saber e de possibilidades de resistência. 
Foucault (1988, p. 134) nos ajuda a refletir sobre esse último ponto dizendo que por mais que as tecnologias políticas invistam em todo o espaço de existência, desde o corpo do indivíduo até as condições de vida da população, a vida sempre "escapa continuamente". Isto significa que sempre há espaço para invenção de novas formas de viver, pois as técnicas de dominação nunca se exercem de uma forma total pelo fato das relações de poder sempre vir acompanhadas das forças de resistência. Essas forças de resistência irão se insurgir contra as práticas biopolíticas a partir do século XIX, apoiadas sobre aquilo que o poder investe: “O 'direito' à vida, ao corpo, à saúde, à satisfação das necessidades [...] foi a réplica política a todos esses novos procedimentos de poder" (Foucault, 1988, p. 136). Temos assim no século $X X$, no Brasil de modo mais incisivo nos anos 1970-80, o fortalecimento de movimentos sociais que reivindicaram e exigiram a construção de políticas sociais que garantissem direitos a partir do protagonismo das populações. Assim, a relação entre políticas públicas, biopolíticas e resistências é complexa e opera permanentemente num jogo de forças e enfrentamentos (Ferreira Neto, 2011).
A experiência da comissão de saúde aqui estudada pode ser inserida nessa série de resistências que faz embate ao manejo biopolítico das políticas públicas, exigindo um olhar singular do Estado face às questões específicas dessa população. Nesse emaranhado de tramas e enfrentamentos, vale apontar que o trabalho articulado dessa comissão não se deu de modo espontâneo, mas foi potencializado por um programa estadual de intervenções sociais, elaborado no contexto de uma universidade pública.

O "Mediação de Conflitos" como política pública de prevenção à criminalidade, segundo Nunes et al. (2009), surgiu através do Programa de Pesquisa e Extensão - Pólos de Cidadania, desenvolvido pela Faculdade de Direito da Universidade Federal de Minas Gerais (UFMG). Como o nascimento do Programa Mediação de Conflitos tem sua origem vinculada ao "Pólos de Cidadania", torna-se necessário explicar, brevemente, $\mathrm{o}$ processo de construção deste último. No trecho a seguir a formação do Pólos de Cidadania, é posta em evidência: "o Programa Pólos de Cidadania começou, em 1995, quase como um grupo de estudos e logo encontrou espaço de atuação como projeto de ensino, pesquisa e extensão universitária". (Universidade Federal de Minas Gerais [UFMG], 2005). Assim, 
pode-se dizer que foi a partir de uma ação social, originária do meio acadêmico, em defesa prioritariamente dos direitos humanos e da emancipação das comunidades à margem social, que o "Pólos de Cidadania" emergiu e, em decorrência disso, o Programa Mediação de Conflitos.

Cabe ressaltar que, em 2004, o Programa Pólos de Cidadania, a partir de um convênio de parceria com a Secretaria de Defesa Social do Governo de Minas Gerais (SEDS), passou a executar o projeto "Núcleo de Mediação e Cidadania" nas periferias de Belo Horizonte e do interior do Estado de Minas Gerais, contando com o apoio e o financiamento daquele órgão público. Mas foi em meados de 2005, conforme Ferreira et al. (2010), que o projeto mencionado tornou-se uma política pública de prevenção à violência e à criminalidade, desenvolvida pela SEDS, especificamente pela Superintendência de Prevenção à Criminalidade (SPEC).

Nessa lógica, o projeto "Núcleo de Mediação e Cidadania" ao ser inserido em uma estrutura política de governo (SEDS/SPEC) tornou-se um Programa, denominado "Mediação de Conflitos". Este passa a ser executado no Núcleo de Prevenção à Criminalidade (NPC), juntamente com o Programa de Controle de Homicídios (Fica Vivo!).

\section{Método}

Compreender a vivência da comissão de saúde como experiência implica em entender o entrelaçamento da “constituição histórica dos discursos, das práticas, das relações de poder e das subjetividades" (Revel, 2005) presentes na prática coletiva daquele grupo. Para tanto, optou-se por realizar uma pesquisa de cunho qualitativo, utilizando-se como estratégia metodológica o estudo de caso. Apoiou-se, deste modo, em procedimentos diversos tanto com relação à produção de dados quanto à análise de informações. Tal prática que articula e combina entre as várias estratégias de investigação, diante de um mesmo fenômeno, é denominada por Minayo (2008) de triangulação de métodos.

No tocante a coleta de dados, utilizou-se como instrumentos os documentos produzidos pelo grupo supracitado e pela equipe técnica do PMC (ofícios, atas de reuniões e listas de presença), no período de 2008 a 2010; as informações obtidas através da observação participante, incluindo aqui os registros feitos no diário de campo; e as entrevistas semidirigidas realizadas, individualmente, com cinco membros da Comissão de Saúde. 
Cabe ressaltar que, por mais que se tenha optado em utilizar os procedimentos metodológicos supracitados na pesquisa, decidiu-se fazer um maior uso do diário de campo, material este considerado de grande valor por ter sido produzido pela pesquisadora a partir da escrita de relatos, contendo informações precisas sobre o desenrolar de cada encontro do grupo e impressões acerca da vida cotidiana dos moradores de Rosaneves e da experiência da Comissão de Saúde. Corroboramos com Barros e Kastrup (2009, pp.70-71) quando dizem que a elaboração do relato, longe de ser um momento burocrático, tem como propósito "possibilitar um retorno à experiência do campo, para que se possa então falar de dentro da experiência e não de fora, ou seja, sobre a experiência".

Em relação às entrevistas semidirigidas, é importante dizer que elas foram realizadas em um momento posterior à saída da pesquisadora do Programa Mediação de Conflitos. Tais entrevistas foram feitas com cinco participantes da Comissão de Saúde, responsáveis pela condução das atividades do grupo.

Sobre as cinco pessoas entrevistadas, todas eram do sexo feminino e possuíam idade variável entre 46 e 51 anos. Todas elas são donas de casa, mas quatro destas exercem algum tipo de atividade informal para ajudar seus maridos nas despesas da casa. Ademais, das cinco entrevistadas, três possuem o ensino fundamental incompleto e duas o ensino médio completo. Todos os nomes dos participantes foram mantidos, a pedido dos mesmos. 


\begin{tabular}{|c|c|c|c|c|c|}
\hline Nome & Valdereza & Rosa & Celma & Eleonora & Silvia \\
\hline Idade & 46 anos & 48 anos & 46 anos & 49 anos & 51 anos \\
\hline Escolaridade & $\begin{array}{c}\text { Ensino } \\
\text { Fundamental } \\
\text { Incompleto }\end{array}$ & $\begin{array}{c}\text { Ensino } \\
\text { Fundamental } \\
\text { Incompleto }\end{array}$ & $\begin{array}{c}\text { Ensino } \\
\text { Médio } \\
\text { Completo }\end{array}$ & $\begin{array}{c}\text { Ensino } \\
\text { Médio } \\
\text { Completo }\end{array}$ & $\begin{array}{c}\text { Ensino } \\
\text { Fundamental } \\
\text { Incompleto }\end{array}$ \\
\hline Estado civil & Casada & Casada & Casada & Solteira & Casada \\
\hline Trabalho & Dona de casa & $\begin{array}{c}\text { Dona de } \\
\text { casa/ } \\
\text { Manicure }\end{array}$ & $\begin{array}{c}\text { Dona de } \\
\text { casa/ Faz } \\
\text { bolos e } \\
\text { salgados } \\
\text { para vender }\end{array}$ & $\begin{array}{c}\text { Dona de } \\
\text { casa/ } \\
\text { Diarista }\end{array}$ & $\begin{array}{c}\text { Dona de } \\
\text { Casa/cuidadora } \\
\text { de idoso }\end{array}$ \\
\hline $\begin{array}{c}\text { Engajamento } \\
\text { cívico antes } \\
\text { da formação } \\
\text { da Comissão } \\
\text { de Saúde. }\end{array}$ & Não. & $\begin{array}{c}\text { Sim. } \\
\text { Associação } \\
\text { de bairro e } \\
\text { ações } \\
\text { comunitárias } \\
\text { ligadas a } \\
\text { Igreja } \\
\text { Católica. }\end{array}$ & Não. & $\begin{array}{c}\text { Sim. } \\
\text { Associação } \\
\text { de bairro e } \\
\text { Conselho } \\
\text { Municipal } \\
\text { de Saúde } \\
\text { (suplente) }\end{array}$ & Não. \\
\hline
\end{tabular}

Tomou-se, então, o objeto de estudo como um acontecimento, ou seja, como um processo de "acontecimentalização". Nas palavras de Foucault (1980) trata-se de abandonar a tendência de explicar determinado acontecimento pelo viés da causalidade única. Assim, o acontecimento deve ser "analisado como processo, um polígono, ou melhor, poliedro de inteligibilidade, cujo número de faces não é previamente definido e nunca pode ser considerado como legitimamente concluído". (Foucault, 2006a, p. 340)

Sendo assim, a análise do objeto de estudo privilegiou um maior número de vetores que corroboraram para a experiência da Comissão de Saúde do bairro Rosaneves se dar dessa maneira, além de procedimentos de produção de dados variados, como se mencionou anteriormente. Isto significa que, além da análise temática e da triangulação de métodos utilizou-se também a técnica da análise do discurso com intuito de 
conseguir investigar os elementos de saber, de poder e de subjetivação presentes na experiência do grupo citado.

\section{Resultados e discussão}

O bairro Rosaneves, localizado no município de Ribeirão das Neves, possui, conforme o diagnóstico comunitário realizado no ano de 2006, aproximadamente seis mil moradores. A precariedade do serviço de saúde é um dos maiores problemas enfrentados pelos moradores do bairro. Observou-se que são muitas as dificuldades enfrentadas pela população no acesso a saúde pública do município, a saber: estrutura física inadequada dos postos de saúde e do hospital, falta de medicamentos e de materiais básicos, ausência de médicos especialistas, equipes incompletas na estratégia Saúde da Família, demora na marcação de consultas e exames, entre outros.

Pode-se dizer que é nesse contexto de "crise" que emerge o grupo, autodenominado de Comissão de Saúde de Rosaneves. Isto porque, a ideia de se criar um grupo, formado por moradores do bairro, para debater e lutar por melhorias no âmbito da saúde surgiu durante a realização do IV Fórum Comunitário, em Rosaneves. Ou seja, a demanda por serviços públicos de saúde em Ribeirão das Neves tornou-se uma urgente questão a ser discutida no município e por isso decidiuse que o IV Fórum Comunitário do bairro Rosaneves, realizado em Dezembro de 2007, teria como tema central a saúde pública. Foi, então, durante esse Fórum, que surge a proposta de criação de uma comissão de saúde como uma das estratégias de ação para buscar melhorias na saúde pública do município. O evento contou com a participação de profissionais do Núcleo de Prevenção à Criminalidade (NPC), de moradores do bairro e de representantes da Secretaria Municipal de Saúde.

Cabe ressaltar que o Fórum Comunitário é uma ação preconizada pela metodologia de trabalho dos Programas de Prevenção à Criminalidade, cujo objetivo é criar um espaço de participação de diversos atores sociais, em comunidades localizadas em áreas marcadas pela exclusão social, na construção local da política de prevenção à criminalidade (Galgani, 2007, p. 76). Nesse sentido, mesmo sendo uma política de base estatal, seu contorno, até o momento, faculta espaços de participação e protagonismo social, o que vai, por vezes, de encontro às ações biopolíticas mais convencionais do Estado, produzindo embates. 
Vale à pena lembrar que, por esta política compor as ações do Plano Estadual de Segurança Pública de Minas Gerais, pauta-se na ideia de que a criminalidade se relaciona a uma série de desvantagens sociais, tais como: urbanização e habitação precária, desemprego, carências no âmbito da saúde, educação, alimentação, lazer. Por isso, é reconhecida a importância dos fóruns comunitários na minimização das problemáticas locais vivenciadas.

No caso do IV Fórum Comunitário, desenvolvido no bairro Rosaneves, salientamos que a proposta da criação do grupo Comissão de Saúde ficou apenas no papel, uma vez que os moradores ainda não haviam se organizado para tal. Destarte, pode-se dizer que foi a partir da atuação do Núcleo de Prevenção à Criminalidade de Rosaneves que a Comissão de Saúde se formou, pois a iniciativa de retomar as ações do fórum partiu dos profissionais dos Programas de Prevenção à Criminalidade.

Inicialmente, a Comissão de Saúde era tida como uma ação de responsabilidade do Núcleo de Prevenção à Criminalidade, especificamente pelo Programa Mediação de Conflitos e Programa Fica Vivo!, mas, posteriormente o grupo passou a ser um caso comunitário do PMC, sendo acompanhado somente por este através do eixo Mediação Comunitária.

Nesse cenário, é importante sublinhar que a Comissão de Saúde não representa uma forma de organização comunitária absolutamente autônoma, posto que a sua criação e o seu desenrolar vinculam-se a figura do Estado, quer dizer, a política pública de prevenção à criminalidade/PMC. Mas, não se pretende dizer com isso que as políticas públicas, necessariamente, nasçam dentro do próprio Estado, pelo contrário, apesar delas serem executadas exclusivamente por este, elas podem ter origem na sociedade por meio de reivindicações e de lutas sociais. De um modo mais preciso, a produção de políticas públicas surge como conexão entre o Estado e a sociedade, num encontro, geralmente tensionado, que agrega forças e interesses díspares, que vão paulatinamente produzindo consensos parciais nos moldes de uma formulação de política negociada. Do ponto de vista da implementação também encontramos um "entre" Estado e sociedade, encarnado nos espaços regionais e locais, onde a política de fato se processa em uma arena com múltiplas forças sociais, onde necessariamente ocorrem variações em relação à formulação da política (Hochman, Arretche, \& Marques, 2007). 
Em um primeiro momento do grupo, observou-se que a condução dos encontros, a elaboração das pautas e os agendamentos das reuniões eram realizados pelos técnicos e pelos estagiários do Programa. Percebeu-se, então, que os participantes da Comissão de Saúde não tinham se apropriado, ainda, da organização e do funcionamento do grupo de forma autônoma.

A partir dos seis meses de existência da Comissão de Saúde esse quadro começou a se alterar. Isto porque, a partir de então, uma série de atividades passa a ser planejada e executada pelos próprios participantes do grupo, refletindo assim tanto na dinâmica dos encontros do grupo com os moradores do bairro, quanto na abertura de um processo de diálogo e negociação com a Secretaria Municipal de Saúde de Ribeirão das Neves, com o Conselho Municipal de Ribeirão das Neves e com a Câmara Municipal de Vereadores de Ribeirão das Neves.

No tocante aos participantes do grupo, importa dizer que a Comissão de Saúde contou, no início, com a participação de seis moradores do bairro, sendo que destes, apenas quatro permaneceram durante os dois primeiros anos de existência do grupo, quais sejam: Nelson, Rosa, Leonora e Valdereza. Cabe ressaltar que os três primeiros, na época, faziam parte da Associação Comunitária do bairro Rosaneves (ASCOBARONE) nas funções, respectivamente, de presidente, vice-presidente e presidente do conselho fiscal. Leonora além de exercer essa função naquela instituição, atuava também como conselheira suplente do Conselho Municipal de Saúde de Ribeirão das Neves. Já Valdereza, dona de casa, não tinha vínculo com nenhuma organização comunitária antes de se engajar na Comissão de Saúde.

Além desses representantes, a Comissão de Saúde de Rosaneves contou com a presença atuante, no final do primeiro ano de existência daquela, de mais três moradores do bairro, cuja participação também contribuiu para o desenvolvimento e amadurecimento do grupo, a saber: Silvia, Celma e Leandro. Vale lembrar que nenhum dos três tinha um engajamento social na comunidade, mas isso não os impediram de abraçar a causa da Comissão de Saúde. Aliás, pelo fato da saúde ser um dos maiores problemas enfrentados pelos moradores do bairro Rosaneves, eles acabaram se mobilizando com a iniciativa do grupo, decidindo assim fazer parte do mesmo. 


\section{PMC, Comissão e o processo grupal}

O estudo, por se apoiar na abordagem qualitativa, especificamente, no estudo de caso da experiência da Comissão de Saúde, não permite fazer ampla generalização dos resultados. Além disso, ao tomar o grupo estudado como um "acontecimento" partiu-se do princípio de que a análise de seu processo não pode ser totalmente concluída e por isso acabada. Isso certamente não impedirá que os leitores desse trabalho encontrem conexões entre este estudo de caso e outras experiências similares que ocorrem em outro contexto. O estudo de caso é singular, mesmo não sendo generalizável à maneira dos estudos experimentais, pode permitir outras conexões com outras experiências. Em consonância com Foucault, acreditamos na potência dos estudos localizados, como ele sempre desenvolveu, possibilitando a criação de diferentes formas de pensamento e análise.

Analisaremos, primeiramente, os aspectos discursivos (saber-poder) do Programa Mediação de Conflitos. Este programa, ao ser inserido no campo das políticas públicas, especificamente na área da segurança pública, é "formatado" pelos planos, decretos, guias, entre outros documentos que sustentam a política estadual de segurança pública. Assim, o
PMC ao ter como propósito a gestão dos fatores de risco e de proteção de determinada comunidade periférica passa, indiretamente, a gerir a vida dos indivíduos e da população. Isso implica dizer que aquele programa ao executar sua prática de trabalho, por meio de seu corpo teóricometodológico, lança mão de técnicas de poder (disciplinar e biopolítica) e de saber. Ou seja, assim como toda política pública, o PMC institui "verdades" a partir de enunciados que dizem aos seus usuários como eles têm que agir ("Sejam participativos e atuantes em sua comunidade"), se comportar ("Sejam cooperativos e solidários entre si"), se relacionar ("Busquem resolver seus conflitos interpessoais através da compreensão e do diálogo"). Ademais, o referido programa ao visar à prevenção à criminalidade busca potencializar a vida da população controlando as variáveis (fatores de risco) que possam interferir no seu equilíbrio. Como resultado disso, pode-se observar efeitos na produção de subjetividade de seus usuários. Ao mesmo tempo em que o programa supracitado assujeita e homogeneíza a vida daqueles, por meio de suas práticas uniformizadoras (universalizantes) e de suas "verdades", ele também abre espaço para a construção de novos modos de vida. Isto porque, a constituição do sujeito, no sentido 
foucaultiano, se dá concomitantemente através de relações de poder-saber e de possibilidades de resistência, colocadas pela mesma experiência.

Nessa lógica, não se pode deixar de pontuar que o Programa Mediação de Conflitos pôde contribuir no processo grupal daquela à medida que os técnicos e os estagiários fomentaram a formação, a organização e a coesão grupal, concomitantemente, com a difusão de informações relacionadas ao modo de funcionamento do SUS, promovendo assim o exercício político dos moradores envolvidos com a "causa comum" do grupo e a produção de autonomia dos mesmos.

Para a análise do processo grupal utilizamos as contribuições de Lapassade (2007) em sua leitura da dialética dos grupos em Sartre. Contudo, tomamos as etapas por ele apresentadas como momentos não necessariamente evolutivos e que por vezes se apresentam de modo concomitante.

A criação de um espaço de luta política, a partir da experiência da Comissão de Saúde, foi fruto de um longo processo, visto que o movimento da transformação (agrupamento-grupo) não acontece de forma linear. Vale lembrar que no início da trajetória da Comissão de Saúde, esta ainda não podia ser visualizada como um grupo. No início, prevalecia a dispersão dos participantes, a nãoreciprocidade entre eles e a inércia prática, ou seja, havia uma "série" de indivíduos. Somente após alguns encontros foi possível visualizar algumas mudanças, a saber: o surgimento de uma ação comum (a luta pela vinda de médicos às equipes de saúde da família do bairro), a realização de um compromisso tácito entre os participantes (Lapassade, 1977). Neste momento pode-se dizer que a Comissão de Saúde pôde ser denominada de fato como um grupo. Posteriormente, observamos a distribuição das tarefas (agendamento das reuniões com os órgãos públicos, elaboração de ofícios, de pautas de reuniões e de atas, etc.), o que contribuiu para a diferenciação das funções dos participantes do grupo.

Viu-se assim aparecer os conflitos devido às pressões exercidas por eles próprios em razão, principalmente, ao não cumprimento das tarefas propostas. Ocorre que, a organização do grupo transformouse em disciplina e em hierarquia, fazendo nascer a institucionalização da Comissão de Saúde. As funções do grupo, então, se tornam obrigações a serem executadas. Assistiu-se com isso a saída de alguns participantes e a entrada de outros. E por fim, observou-se a tentativa do grupo em engendrar a burocratização (elaboração de 
um estatuto, realização de uma votação), mas não conseguimos visualizar mudanças no formato do grupo após esse fato.

Nesse movimento do grupo, visualizado ao longo de seu desenvolvimento, a Comissão de Saúde participou de reuniões com diversos órgãos públicos (Conselho Municipal de Saúde de Ribeirão das Neves, Secretaria Municipal de Saúde, Câmara Municipal de Vereadores) com intuito de reivindicar e de propor alternativas para melhorar o serviço público de saúde do município de Ribeirão das Neves. Importa salientar que a luta cotidiana do grupo foi marcada pela tensão entre os dois pólos dispersão-fusão. É, então, nesse movimento, sempre inacabado e instável, que o grupo é atravessado pelas relações de poder (entre os próprios participantes da Comissão de Saúde; entre estes e os profissionais do PMC; entre os representantes dos órgãos públicos e participantes do grupo). Isto significa que, em todas as relações humanas o poder encontra-se presente à medida que cada pessoa procura, de alguma maneira, dirigir a conduta do outro.

Em relação aos avanços, podemos destacar que houve um progressivo envolvimento da Comissão gerando intervenções no cotidiano da saúde. Valdereza, em um dos encontros da Comissão de Saúde, comentou sobre a sua conversa com uma das enfermeiras da estratégia de Saúde da Família e a partir disso expôs para o grupo a importância de se criar um espaço de diálogo entre a Comissão de Saúde com as equipes responsáveis pela Saúde da Família do bairro Rosaneves. Tal ideia foi logo aceita pelos participantes presentes na reunião. Leonora propôs também de convidar os profissionais das equipes de saúde da família (ESF) para comparecerem, semanalmente, nas reuniões do grupo a fim de estabelecer uma parceria de trabalho entre eles.

Sendo assim, os representantes do grupo enviaram um ofício à Coordenadoria da Atenção Básica solicitando uma reunião com as três equipes e uma autorização para que um dos profissionais de cada equipe pudesse ser liberado de suas rotinas para participarem toda semana das reuniões da Comissão de Saúde. As reuniões foram realizadas, nos espaços das Equipes de Saúde da Família, com cada equipe de trabalho e em dias diferentes. Nas três reuniões, os representantes do grupo salientaram que a proposta da Comissão de Saúde é lutar pelo acesso dos moradores de Rosaneves a um serviço de saúde de mais qualidade no bairro e no município de Ribeirão das Neves, assim como por uma maior cobertura da população a tais serviços. Nessa perspectiva Nelson 
pontuou que um dos objetivos da Comissão de Saúde é reivindicar para que as três unidades de saúde tenham um quadro de funcionários completo, o que historicamente não vinha ocorrendo.

Outro ganho decorrente dessa aproximação com os profissionais da saúde foi um acordo que garantia a presença de um agente comunitário de cada ESF. A presença destes contribuiu para aproximar a comunidade das três equipes de saúde da família. Isso permitiu uma maior apropriação das questões ligadas aos serviços, permitindo a elaboração de propostas mais condizentes com a realidade municipal. Assim, a proposta de criação de uma Policlínica no bairro Rosaneves foi substituída, pela proposta da construção de uma Unidade Básica de Referência no bairro, mais viável na conjuntura daquele momento. Isso é consubstanciado na fala de Celma: "Por fazer parte da comissão passei a ler mais, passei a conhecer cada código, passei a procurar pra ver se realmente é assim. Às vezes em uma reunião eles falam alguma coisa que eu não sei, depois eu vou atrás, passei a fuçar, a procurar, ver se é isso mesmo".

Houve também um crescimento na capacitação da Comissão para uma abordagem mais substantiva dos problemas da saúde, gerando um reconhecimento da
Comissão como interlocutora importante pelos gestores municipais. Em reunião do grupo com a Secretária de Saúde que visou à apresentação do grupo, a exposição do Projeto "Qualidade de vida e melhoria da saúde no bairro Rosaneves", o esclarecimento de dúvidas com relação aos serviços de saúde executados e a construção de uma parceria de trabalho entre ambos. Além de um estagiário do Programa Mediação de Conflitos e de alguns representantes do grupo, Elisa, Rosa, Valdereza e Leo, estiveram presentes a Coordenadora da Atenção Básica, uma profissional responsável pela Ouvidoria e a gerente de Recursos Humanos da Saúde.

Como em todas as reuniões da Comissão de Saúde com os órgãos competentes foi elaborado um roteiro de perguntas a serem feitas a Secretária Municipal de Saúde, a saber: "Por que as equipes das estratégias de saúde da família, que atendem os moradores do Rosaneves, estão incompletas?"; "O que tem sido feito para resolver essa situação que dura há mais de dois anos?" e "Foi aprovado pelo Conselho de Saúde uma verba de oitenta milhões para a saúde do município. Como vocês pensam em utilizar essa verba? Quais os projetos da Secretaria de Saúde?”. A reunião foi encerrada com a definição de que a Coordenadora da Atenção Básica iria 
participar dos encontros da Comissão de Saúde a cada dois meses.

Observou-se que, a partir do processo grupal, as estratégias de resistência não se apresentaram de modo fluído e contínuo, visto que em certos momentos elas tendiam a se cristalizar e ocasionar um estado de paralização. Pudemos observar que, a partir da cristalização e de um bloqueio das relações entre os indivíduos, o grupo remontava ao estágio de dispersão acarretando algumas implicações quanto ao processo grupal da Comissão de Saúde, a saber: desânimo nos participantes e nos próprios profissionais do PMC, saída de algumas pessoas, ausência de perspectiva em relação ao rumo do grupo, falta de ação (inérciaprática), não-reciprocidade entre os participantes, rotina do grupo regida pela disciplina (pressões e coerções), repetição e rigidez (reunião com a comunidadeelaboração de ofício- reunião com os órgãos públicos), entre outras. Notamos, assim, que em vários momentos a Comissão de Saúde encontrou-se imersa nos estados de paralização, o que dificultou a construção de novas ideias, de novos caminhos, de novas possibilidades de ação e de relação.

Já nos momentos de fusão do coletivo foi possível vislumbrarmos "as condições de possibilidade da experiência social" (Lapassade, 1977, p. 256). Isto se deve ao fato, principalmente, da presença no grupo de uma finalidade comum (a luta pelo acesso e por melhorias no âmbito da saúde pública de Ribeirão das Neves), a reelaboração de práticas e de ações, a criação de alternativas face às problemáticas coletivas, o exercício crítico com relação ao conhecimento adquirido, a produção de autonomia, a materialização dos projetos coletivos (e individuais), as mudanças nas relações sociais (interna e externa) do grupo. $\mathrm{O}$ aumento da autonomia se vincula a dimensão política e ética à medida que as estratégias de resistência criam "brechas" para a invenção de novas possibilidades de vida, novos modos de subjetivação. Algumas falas dos participantes da Comissão de Saúde apontam aspectos relativos a esta questão:

\footnotetext{
“[...] hoje nós somos pessoas mais conscientes dos nossos direitos, somos pessoas mais participativas [...] Hoje a gente tem mais credibilidade, mais acesso [...]" (Rosa, entrevista pessoal, 16 de julho, 2010)

E valeu a pena, por que assim que a gente começou a trabalhar a gente conseguiu trazer um médico, mesmo que ele ficou pouco tempo, mas veio um médico [...] (Silvia, entrevista pessoal, 16 de julho, 2010)
} 
“[...] muitos direitos da gente a gente não sabia que tinha, por exemplo, eu não sabia de nada, eu era cega, literalmente cega. Hoje ninguém me passa a perna. [...] então, em qualquer lugar que eu for, onde quer que seja, eu sei os meus direitos". (Valdereza, entrevista pessoal, 16 de julho, 2010).

A experiência da Comissão de Saúde se constituiu, "através das práticas de sujeição ou, de maneira mais autônoma, através de práticas de liberação, de liberdade" (Foucault, 2006, p. 291). Assistiu-se, assim, durante o desenrolar daquele grupo tanto momentos de assujeitamento, como momentos de resistência. Nesta ocasião, dimensões de caráter não só contestatório foram mobilizadas, mas também dimensões afetivas, sociais, éticas, políticas, promovendo assim mudanças nas atitudes, nas relações, nos pensamentos, nos olhares, enfim, nas formas de vida dos representantes da Comissão de Saúde. Conforme Revel (2005, p. 74) “a resistência é a possibilidade de criar espaços de lutas e de agenciar possibilidades de transformação em toda a parte", incluindo aqui os vários aspectos da vida dos indivíduos, aspectos estes que perpassam as questões materiais e sociais pelo fato de atingir também aspectos atinentes a subjetividade dos mesmos. Podemos visualizar estas questões quando a participante Valdereza diz que hoje "ninguém me passa a perna mais"; ou quando Celma tece o comentário "hoje eu sou alguém notada pela comunidade"; ou ainda, quando Rosa afirma que "A pressão popular é importante. O povo não pode pagar com vida. Até em uma bala nós pagamos impostos. Não estamos pedindo um favor, a saúde é um direito nosso. O povo cansou, a situação já passou do limite".

\section{Considerações finais}

A pesquisa ajudou a compreender a trajetória da Comissão de Saúde do bairro Rosaneves de forma crítica e reflexiva. Pensar sobre a história do grupo possibilitou a reflexão sobre os diversos atravessamentos que permearam a experiência da Comissão de Saúde. Aqui, pode-se citar os discursos (elementos de saber e de poder) materializados na prática do Programa Mediação de Conflitos, as relações de poder (elementos de poder) presentes em todas as relações sociais do grupo e os elementos de subjetivação (sentimentos, pensamentos, desejos, maiores graus de autonomia) provocados, numa escala pessoal quanto coletiva, a partir do processo grupal.

Isso indica que a construção dos processos de subjetivação se dá conectada 
aos processos sociais, visto que a subjetivação a qual nos referimos nesta pesquisa não se liga a uma interioridade psicológica, mas aos processos plurais e coletivos pelos quais nos tornamos o que somos. Na verdade, o mais interessante no tocante à experiência da Comissão de Saúde é o fato dos participantes saírem dela modificadas, numa proporção maior do que as modificações obtidas nas mudanças buscadas nos serviços de saúde. Com efeito, essas pessoas puderam transformar a si a partir da sua conexão com o outro e com o espaço onde estão inseridas. Nesse sentido, a prática grupal estudada nos revelou ser uma luta social e subjetiva à medida que possibilitou a visibilidade das demandas coletivas do bairro Rosaneves como também a visibilidade das pessoas.

\section{Referências}

Barros, L. P. de, \& Kastrup, V. (2009). Cartografar é acompanhar processos. In Passos, E., Kastrup, V., \& Escóssia, L. de. (Orgs.). Pistas do método da cartografia: pesquisaintervenção e produção de subjetividade (pp. 52-75). Porto Alegre: Sulina.

Ferreira, B. M., Almeida, C. R., Lopes, C. J. R., Prates, E. C., Mendes, F.C.S.,
Teixeira, G. N., et. al. (2010). Concepção teórica e prática do Programa Mediação de Conflitos no contexto das políticas públicas de prevenção à criminalidade no Estado de Minas Gerais. In Governo de Minas. Mediação e Cidadania: Programa Mediação de Conflitosano 2010. (pp. 10-117). Belo Horizonte: Arraes Editores.

Ferreira, J. L. Neto (2011). Psicologia, políticas públicas e o SUS. São Paulo: Escuta; Belo Horizonte: Fapemig.

Foucault, M. (1988). História da sexualidade I: a vontade de saber $\left(13^{\mathrm{a}}\right.$ ed.). (M.T, da Costa, \& J. A. Guilhon, Trad.) Rio de Janeiro: Graal. (Obra original publicada em 1976).

Foucault, M. (2005). Em defesa da sociedade: Curso dado no Collège de France (1975- 1976). (M. E. Galvão, Trad.). São Paulo: Martins Fontes.

Foucault, M. "Acontecimentalizar" (2006a). Foucault, M. Estratégia poder-saber. (Vol. 4, pp. 339-341). (Coleção Ditos e Escritos). Rio de Janeiro: Forense Universitária. 
Foucault, M. (2006b). Ética, sexualidade e política. (Vol. 5). (Coleção Ditos e Escritos). Rio de Janeiro: Forense Universitária.

Foucault, M. (2008). Segurança, território, população: Curso dado no Collège de France (1977-1978). (E. Brandão, Trad.). São Paulo: Martins Fontes. (Obra original publicada em 1978).

Foucault, M. (2009). Vigiar e punir: Nascimento da Prisão. ( $36^{\mathrm{a}}$ ed.). (R. Ramalhete, Trad.). Petrópolis: Vozes. (Obra original publicada em 1975).

Foucault, M. (2011). Microfísica de Poder (29a ed.). (R. Machado, Trad.). Rio de Janeiro: Graal. (Obra original publicada em 1979).

Hochman, G.; Arretche, M. \& Marques, E. (org) (2007). Políticas públicas no Brasil. Rio de Janeiro: Editora FIOCRUZ

Galgani, Felipe. (2007). Os planos locais de prevenção e o conceito de capital social. In Governo de Minas. Entremeios: Mediação, Prevenção e Cidadania. (pp. 10-19). Belo Horizonte: UFMG.
Guareschi, N.M.F., Lara, L., \& Adegas, M.A. (2010) Políticas públicas entre o sujeito de direitos e o homo oeconomicus, Psico $\Psi, 41$ (3), 332339.

Lapassade, G. (1977). Grupos, organizações e instituições. Rio de Janeiro: Francisco Alves.

Minayo, M. C. de S., Assis, S. G. de, \& Souza, E. R. de. (Orgs.). (2005). Avaliação por triangulação de métodos: abordagem de programas sociais $\left(20^{\mathrm{a}}\right.$ ed.). Rio de Janeiro: Fiocruz.

Nunes, A. C. C., Leandro, A. G. L., Imai, C. A. P., Almeida, C.R., Resende, F.V., Cruz, G. F. C., Cambraia, K. A. B., Clementino, P. A, \& Rodrigues, S. M. A. (2009). Concepção teórica e prática do Programa Mediação de Conflitos no contexto das políticas públicas de prevenção à criminalidade no Estado de Minas Gerais. In Governo de Minas. Programa Mediação de Conflitos (pp. 29-118). Belo Horizonte: IUS.

Revel, J. (2005). Michel Foucault: conceitos essenciais. São Carlos: Claraluz. 
Rodrigues, M. M. A. (2010). Folha

Explica: Políticas Públicas. São

Paulo: Publifolha.

Santos, C. (2006). Políticas Públicas: uma revisão da literatura, Sociologias, ano 8 (16), pp. 20-45.

Universidade Federal de Minas Gerais. Faculdade de direito. Pólos de Cidadania: Cidadãos de fato e de direito. Diversa, Ano 03, no 08, out. 2005. Recuperado em 17 fevereiro, 2011, de http://www.ufmg.br/diversa/8/polosd ecidadania.htm

\section{Ana Carolina Perella: Psicóloga}

Especialista em Psicodrama pelo Instituto Mineiro de Psicocrama Levi Jacob Mineiro. Mestre em Psicologia pela Pontifícia Universidade Católica de Minas Gerais.

E-mail: ana.carolina.perrella@hotmail.com

João Leite Ferreira Neto: Psicólogo, mestre em Filosofia, doutor em Psicologia e pós-doutor em Psicologia Social pela UERJ. Professor adjunto III do Programa de Pós-Graduação em Psicologia da Pontifícia Universidade Católica de Minas Gerais, orientador de mestrado e doutorado, e técnico superior de saúde da Prefeitura de Belo Horizonte. 
